\title{
ELF Regimen
}

National Cancer Institute

\section{Source}

National Cancer Institute. ELFRegimen. NCI Thesaurus. Code C64786.

A regimen consisting of etoposide, leucovorin and fluorouracil used for the treatment of advanced-stage gastric cancer. 